Check for updates

Cite this: RSC Adv., 2017, 7, 19464

Received 12th January 2017

Accepted 18th March 2017

DOI: $10.1039 / c 7 r a 00477 j$

rsc.li/rsc-advances

\section{Dynamics of rapid starch gelatinization and total phenolic thermomechanical destruction moderated via rice bio-extrusion with alpha- amylase activation}

\author{
Enbo $\mathrm{Xu}^{\mathrm{ab}}$ Zhengzong $\mathrm{Wu}^{\mathrm{ab}}$ Aiquan Jiao, ${ }^{\mathrm{ab}}$ Jie Long, ${ }^{\mathrm{ab}}$ Jingpeng $\mathrm{Li}^{\mathrm{ab}}$ \\ and Zhengyu Jin (iD *ab
}

\begin{abstract}
The simultaneous extrusion and enzymatic hydrolysis (bio-extrusion) processing of starchy food materials shows better bioaccessibility of various bioactive compounds, while its mechanism as well as the conditions controlling it are still undetermined for industrial application. The aim of this study was to investigate the influence of bio-extrusion on the kinetics of total phenolics as rapid starch gelatinization occurred. Glutinous rice was primarily extruded with/without thermostable $\alpha$-amylase $(0-1 \%$ at different feed rates $\left(F, 1.5-3.0 \mathrm{~kg} \mathrm{~h}^{-1}\right)$, screw speeds $(N, 100-200 \mathrm{rpm})$, moisture content $(M, 22-38 \%)$ and barrel temperature $\left(T, 80-100^{\circ} \mathrm{C}\right)$. High-efficiency enzymatic extrusion (with $F$ and $N$ as independent variables) was then conducted using response surface methodology when controlled $T$ and $M$ were consistently stable for enzymatic activity. $F, N, M$ and $T$ all affected the degradation rate constants of phenolics $\left(k_{\mathrm{P}}\right)$ and starch $\left(k_{G}\right)$. The original positive relationship between $k_{P}$ and $k_{G}$ was inverted when amylase was introduced into the extrusion process. The activation energy $(E)$ of total phenolic destruction increased from 37.49 to $70.30 \mathrm{~kJ} \mathrm{~mol}^{-1}$, mainly because of the great decrease in die pressure, special mechanical energy and shearing action caused by the enzymatic hydrolysis of starch.
\end{abstract}

\section{Introduction}

The utilization of bio-resources (e.g., glucose, fructose, sucrose, dimeric sugars and polymeric carbohydrates like starch and cellulose) has dramatically increased with technological advancements to meet the exponential economical and demographic growth of both developed and developing countries including India and China. ${ }^{1-3}$ It is of interest to use thermochemical/thermomechanical technologies combined with various catalysts (enzymes, inorganics, acids, alkalis, nanomaterials, etc.) in the degradation and conversion of biomass, cash crops or agro-waste cereals as well as the extraction of some special matter from bio-resources. ${ }^{1,2,4-9}$ In this, extrusion technology combined with enzymatic action is widely applied not only in fuel and bio-energy (such as bioethanol) industries but also in the food production of syrup or fermented beverages. ${ }^{9-14}$

Conventional extrusion is popular for bio-resource processing due to its strong performance of cooperative mixing, shearing and kneading to produce desirable texture, shape or

${ }^{a}$ The State Key Lab of Food Science and Technology, School of Food Science and Technology, Jiangnan University, 1800 Lihu Road, Wuxi 214122, China. E-mail: fpcenter@jiangnan.edu.cn; Fax: +86-510-85913299; Tel: +86-510-85913299

${ }^{b}$ Synergetic Innovation Center of Food Safety and Nutrition, Jiangnan University, Wuxi 214122, China physicochemical reactions. For starchy material, gelatinization occurs in the more accessible and amorphous intermicellar areas with the weakest bonding. ${ }^{15}$ Except for thermal energy input, starch resulted in more gelatinization, degradation and digestion, undergoing the mechanical impact and shear stress of the extruder, especially under extreme conditions. ${ }^{16,17}$ However, mankind does not always accept the over-processing of edible sources due to the avoidance of the thermal and mechanical impact on those trace nutritional or functional substances (e.g., polyphenols, flavonoids, vitamins) that are vulnerable to loss. ${ }^{18-20}$

In recent years, consumer demand for extruded food products that are rich in bioactive compounds has gradually been increasing in consideration of the short-time processing time which is characteristic of extrusion, giving a potential advantage for retaining phenolics compared to other heating treatments such as boiling, blanching and evaporation which often require heating for several hours. ${ }^{18,21}$ These foods are mostly made from cereals or plants with abundant starch and phenolic compounds, which have great relevance for human nutrition and health attributed to their diverse bioactivities of antioxidation, anti-inflammation, anti-proliferation and modulation of signal transduction..$^{22}$ Nevertheless, the relative superiority of extrusion is not obvious as many authors have still found a great loss (more than 50\%) of phenolics during 
extrusion. ${ }^{20,23,24}$ This dilemma was somewhat reversed when the thermostable $\alpha$-amylase was introduced into cereal extrusion (mainly to achieve a high degree of starch gelatinization and liquefaction in the industries of starch saccharification, cake making, ethanol fermentation and liquor brewing) because the phenolics seem to be indirectly protected both in free and bound forms., ${ }^{3,1925,26}$ The mechanism of rapid starch gelatinization coupled with total phenolic retention during bioextrusion is still ambiguous, in spite of the otherwise complex impact of extrusion processing (without an enzyme catalyst) on the chemical and antioxidative profile, considering the multiple operating factors of temperature, moisture content, shear force, local friction and mechanical energy. ${ }^{18}$ Thus it is worth following the idea of modeling reaction kinetics for food ingredients in extrusion cooking that have been developed separately for starch gelatinization and degradation, ${ }^{\mathbf{1 5 , 1 6 , 2 7 - 2 9}}$ amino acid loss $^{30}$ vitamin destruction ${ }^{31,32}$ and phenolic compounds. ${ }^{21,33}$ Therefore, the main objectives of this study were to (1) reveal the dynamic relationship between rapid starch gelatinization and total phenolic destruction during traditional and enzymatic extrusion and (2) determine the critical factors of phenolic retention for high-efficiency enzymatic extrusion as industrial utilization.

\section{Theory}

The kinetics of thermal loss of food components or properties can be described by a general model as follows:

$$
\frac{\mathrm{d} C}{\mathrm{~d} t}=-k C^{\zeta}
$$

where $C$ is the concentration of a component, $t$ is the reaction time, $k$ is the reaction rate constant and $\zeta$ is the reaction order. Results from Cai and Diosady, ${ }^{27}$ Davidson et al. ${ }^{28}$ and Hirth et $a{ }^{21}$ have shown that both the starch gelatinization and phenolic destruction during extrusion tend to be first-order reactions. Hence, the rate constants of starch gelatinization $\left(k_{\mathrm{G}}\right)$ and total phenolic destruction $\left(k_{\mathrm{P}}\right)$ were calculated from a simple prediction using eqn (2) and (3):

$$
\begin{gathered}
k_{\mathrm{G}}=-\ln \frac{\left((1-f) / f_{0}\right)}{t_{\mathrm{m}}} \\
k_{\mathrm{P}}=-\ln \frac{\left(c / c_{0}\right)}{t_{\mathrm{m}}}
\end{gathered}
$$

where $f$ and $c$ are the concentrations of gelatinized starch and total phenolics, respectively, after extrusion, $c_{0}$ and $f_{0}$ are the concentrations of gelatinized starch and total phenolics, respectively, prior to extrusion, and $t_{\mathrm{m}}$ is the mean residence time of the extrusion process. Among these, $t_{\mathrm{m}}$ as well as variance $\left(\sigma^{2}\right)$ and Peclet number (Pe, representing the degree of axial mixing inversely) are mathematically calculated according to Levenspiel $^{34}$ :

$$
t_{\mathrm{m}}=\int_{0}^{\infty} t E(t) \mathrm{d} t=\frac{\sum t_{\mathrm{i}} C_{\mathrm{i}} \Delta t_{\mathrm{i}}}{\sum C_{\mathrm{i}} \Delta t_{\mathrm{i}}}
$$

$$
\begin{gathered}
\sigma^{2}=\frac{\sum\left(t_{\mathrm{i}}-t_{\mathrm{m}}\right)^{2} C_{\mathrm{i}} \Delta t_{\mathrm{i}}}{\sum C_{\mathrm{i}} \Delta t_{\mathrm{i}}}=\frac{\sum t_{\mathrm{i}}{ }^{2} C_{\mathrm{i}} \Delta t_{\mathrm{i}}}{\sum C_{\mathrm{i}} \Delta t_{\mathrm{i}}}-t_{\mathrm{m}}{ }^{2} \\
\sigma_{\theta}{ }^{2}=\frac{\sigma^{2}}{t_{\mathrm{m}}{ }^{2}}=\frac{2}{\mathrm{Pe}}-\frac{2}{\mathrm{Pe}^{2}}\left(1-\mathrm{e}^{-\mathrm{Pe}}\right)
\end{gathered}
$$

where $C(t)$ is the tracer concentration, $E(t)$ is the exit age distribution $\left(\mathrm{s}^{-1}\right), \Delta t$ is the time interval and $\sigma_{\theta}$ is the standardized $\sigma$. When axial mixing of extrusion processing was taken into account, $k_{\mathrm{G}}$ and $k_{\mathrm{P}}$ could be calculated more accurately using eqn (7) and (8):

$$
\begin{gathered}
\frac{1-f}{f_{0}}=\sum_{i}^{\infty} \exp \left(-k_{\mathrm{G}} t_{i}\right) E\left(t_{i}\right) \Delta t_{i} \\
\frac{c}{c_{0}}=\sum_{i}^{\infty} \exp \left(-k_{\mathrm{P}} t_{i}\right) E\left(t_{i}\right) \Delta t_{i}
\end{gathered}
$$

Generally, the temperature dependence of a reaction rate constant obeys the well-known Arrhenius relation: ${ }^{35}$

$$
k=k_{0} \exp \left(-\frac{E}{R(T+273.15)}\right)
$$

where $k_{0}$ is the pre-exponential factor, $E$ is the activation energy (thermal-induced reaction for eqn (9)), $R$ is the universal gas constant and $T$ is the processing temperature. When moisture content $(M)$ and feed rate $(F)$ combined with screw speed $(N)$, or shear-induced degradation are taken into account, eqn (9) can be revised according to eqn (10), (11) and (12), respectively, as follows: ${ }^{16,27,31,32}$

$$
\begin{aligned}
& k=k_{0} \exp \left(-\frac{E}{R(T+273.15)}+\lambda_{\mathrm{m}} M+\lambda_{\mathrm{n}} N\right) \\
& k=k_{0} \exp \left(-\frac{E}{R(T+273.15)}+\lambda_{\mathrm{f}} F+\lambda_{\mathrm{n}} N\right) \\
& k=k_{0} \exp \left(-\frac{E_{0}}{R(T+273.15)}+\frac{\beta G^{n} \bar{\tau}}{T+273.15}\right)
\end{aligned}
$$

where $E_{0}$ is the activation energy in a shear-less environment, $\beta$ is the activation volume, $G$ is the geometrical coefficient, $n$ is the flow behavior index, $\tau$ is the proportionality constant for shear stress and $\lambda_{\mathrm{m}}, \lambda_{\mathrm{f}}, \lambda_{\mathrm{n}}$ are the dependence parameters of $M$, $F$ and $N$, respectively, calculated by a genetic algorithm. Among these, $\tau$ and $n$ can be calculated as follows:

$$
\begin{gathered}
\tau=\eta \gamma \\
\eta=\eta_{0} \gamma^{n-1} \exp \left(\frac{E_{\mathrm{a}}}{R(T+273.15)}-\lambda_{\mathrm{m}} M\right) \\
\gamma=G N \\
\tau=G^{n} \bar{\tau}
\end{gathered}
$$


where $E_{\mathrm{a}}$ is the activation energy of flow, $\eta$ is apparent viscosity, $\eta_{0}$ is a pre-exponential factor of apparent viscosity and $\gamma$ is the shear rate.

\section{Materials and methods}

\subsection{Materials}

Non-pigmented glutinous rice (Oryza sativa L.) of commercial cultivation rich in amylopectin and phenolics was purchased from a local market and milled to pass through a $0.6 \mathrm{~mm}$ screen. The thermostable liquid $\alpha$-amylase Termamyl $120 \mathrm{~L}$ (from Bacillus licheniformis) was used for bio-extrusion with an activity of $120 \mathrm{KNU} \mathrm{g}^{-1}$, an optimum pH of 6-8 and a density of $1.2 \mathrm{~g} \mathrm{ml}^{-1}$ (Novozymes, Beijing, China). The dye tracer (Erythrosin B sodium salt) for RTD was purchased from Sigma-Aldrich Co., Ltd. (Shanghai, China). Gallic acid (GA), 1,1-diphenyl-2picryl-hydrazyl (DPPH) and 2,5,7,8-tetramethylchroman-2carboxylic acid (Trolox) were purchased from Sigma-Aldrich (Shanghai, China). Folin-Ciocalteu reagent, sodium acetate and sodium carbonate were obtained from Sinopharm Chemical Reagent Co., Ltd. (Shanghai, China). Methanol and ethanol were obtained from Aladdin Industrial Inc. (Shanghai, China).

\subsection{Extrusion processing}

A laboratory TSE 24 MC (Thermo scientific, MA, USA) corotating twin-screw extruder was used for the trials (traditional extrusion, TE and enzymatic extrusion, EE). The extruder has a barrel length to diameter ratio of $25: 1$ and its maximum single-shaft torque, temperature, pressure and screw speed were $52.5 \mathrm{Nm}, 400{ }^{\circ} \mathrm{C}, 10000 \mathrm{psi}$ and $500 \mathrm{rpm}$, respectively. Rice flour for TE or EE trials was pre-mixed with deionized water (22$38 \%, \mathrm{db})$ and thermostable $\alpha$-amylase $(0-1 \%$, db of starch) (Table 1) in a ribbon blender for $10 \mathrm{~min}$, then put into plastic bags and stored at $4{ }^{\circ} \mathrm{C}$ overnight for the equal distribution of moisture and enzyme. Another $2 \mathrm{~h}$ was required for the stored mixtures to equilibrate at room temperature, while the enzyme activity can be negligible prior to extrusion. During the extrusion process, the samples were firstly transferred into a vertical feed hopper based on set feed rates in the range of $0.6-3.4 \mathrm{~kg}$ $\mathrm{h}^{-1}$ according to Tables 1 and 2 , then conveyed, mixed, kneaded and heated through the barrel journey (600 $\mathrm{mm}$ length) with four heating zones $\left(50,60\right.$ and $70^{\circ} \mathrm{C}$ for zones 1,2 and 3 in turn, while the fourth section was adjusted between 80 and $100{ }^{\circ} \mathrm{C}$ according to Table 1 ), and finally squeezed out of the barrel die with a single circular nozzle (diameter $6 \mathrm{~mm}$ ). The screw speed of the entire process was controlled in the range of 60-200 rpm according to Tables 1 and 2. After extrusion, the extrudate of TE/ EE was freeze-dried at $-40{ }^{\circ} \mathrm{C}$ and stored at $-20{ }^{\circ} \mathrm{C}$ for further analysis.

\subsection{Experimental design}

3.3.1. Initial design. An initial design was performed to investigate the effect of different operating variables on the phenolic destruction during EE. Briefly, 19 treatments of five factors, i.e., enzyme concentration (level: $0,0.5,1 \%$, $\mathrm{db}$ of starch), feed rate ( $F$, level: $1.50,2.25,3.00 \mathrm{~kg} \mathrm{~h}^{-1}$ ), screw speed
( $N$, level: 100, 150, $200 \mathrm{rpm}$ ), moisture content ( $M$, level: 22, 30, $38 \mathrm{rpm}$ ) and barrel temperature ( $T$, level: 80, 90, $100{ }^{\circ} \mathrm{C}$ ), were conducted (Table 1). The EE trials for this part were defined as "general enzymatic extrusion" (only in this study) considering the unstable hydrolysis of thermostable $\alpha$-amylase to the starch substrate under a wide range of moisture and temperature conditions.

3.3.2. Response surface methodology (RSM). A severe environment would transform enzymatic extrusion to traditional extrusion when enzyme inactivation occurs, which has no significance for the food industry. Thus, we controlled MC and BT (at $38 \%$ and $100{ }^{\circ} \mathrm{C}$, respectively) for amylase $(1 \%$, db of starch), and only determined FR and SS as operating parameters by a second-order central composite design (CCD) (Table 2). The EE trials for this part were defined as "high-efficiency enzymatic extrusion" (only in this study), and were fitted by a second-order polynomial model:

$$
Y=c_{0} \sum_{i=1}^{2} c_{i} X_{i}+\sum_{i=1}^{2} c_{i i} X_{i}^{2}+\sum \sum_{i<j=1}^{2} c_{i j} X_{i} X_{j}
$$

where $c_{0}, c_{i}, c_{i i}$ and $c_{i j}$ are the coefficients for the intercept, linear, quadratic and interactive effects, respectively, $X_{i}$ and $X_{j}$ are independent variables and $Y$ is the dependent variable.

\subsection{Determination of processing parameters}

3.4.1. Product temperature (PT), die pressure (DP) and specific mechanical energy (SME). The processing parameters (PT, ${ }^{\circ} \mathrm{C}$ and DP, Mpa) of the extrusion were recorded by a probe set in the last barrel section of the extruder. SME $\left(\mathrm{kJ} \mathrm{kg}^{-1}\right)$ was calculated from $F, N$ and torque $(\phi, \mathrm{Nm})$ as follows:

$$
\mathrm{SME}=\frac{2 \pi(N / 60) \phi}{F}
$$

3.4.2. Residence time distribution (RTD). The RTD was measured for each trial by a pulse stimulus response technique by the methods of Lin and Armstrong, ${ }^{36}$ with a little modification (red dye tracer: rice flour $=1: 10$ ). The value $a^{*}$ (redness $(+) /$ greenness $(-))$ of the ground samples was then determined in triplicate by a Chroma meter UltraScan Pro 1166 (HunterLab Inc., VA, USA) to calculate the dye concentration.

\subsection{Determination of response values}

3.5.1. Extent of gelatinization (GE). GE was measured by the method of Guha et al., ${ }^{17}$ calculated from the pasting profile of treated rice via a RVA 4500 rapid visco analyzer (Perten Instruments Inc., Sydney, Australia). A modified procedure of RVA was performed, as described in a previous report, ${ }^{37}$ considering the extremely low levels of viscosity of bio-extruded rice (the method of DSC for GE is not sensitive when no areas occur).

3.5.2. Total phenolic content (TPC) and total antioxidant activity (TAA). The TPCs of each sample expressed as free and bound forms were determined according to the Folin-Ciocalteu spectrophotometric method. $^{38}$ The TAA of each sample was 


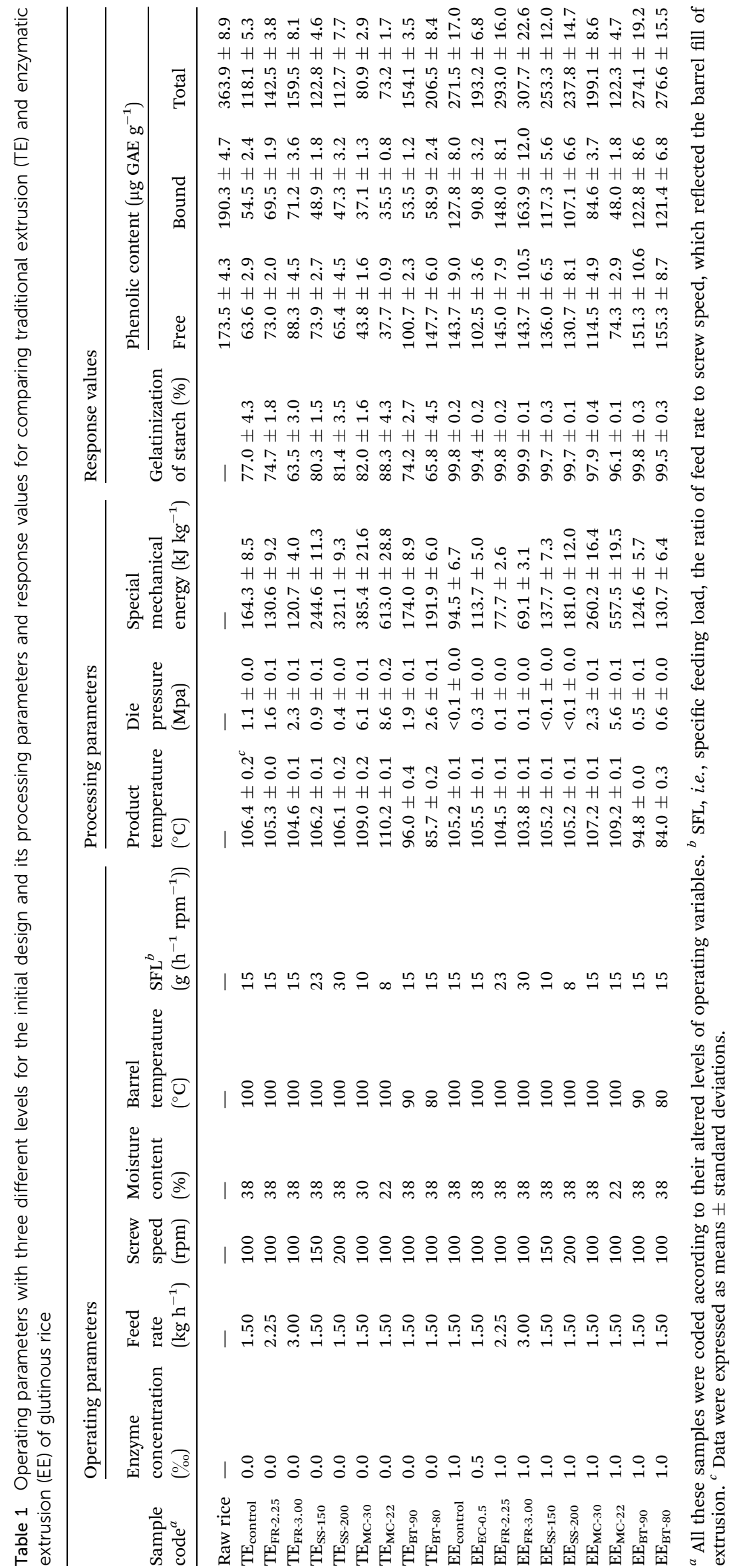


commonly based on the decolorization of a DPPH radical using the method of Brand-Willimas et al. ${ }^{39}$

\subsection{Statistical analysis}

The experimental data were analyzed using Statistical Product and Service Solutions (SPSS) version 16.0 (SPSS Inc., Chicago, IL, USA) and First optimization (1stOpt) version 5.5 (7D-Soft High Technology Inc., Beijing, China). Data were reported as mean \pm standard deviation.

\section{Results and discussion}

\subsection{Kinetic effects of operating parameters}

When thermostable $\alpha$-amylase was introduced, the reactions in relation to starch combined with some bioactives were of the utmost importance to investigate during extrusion. The effects of different operating parameters on their degradation or destruction are shown in Table 1 and Fig. 1, and the corresponding rate constants $k_{\mathrm{G}}$ and $k_{\mathrm{P}}$ are shown in Table 3 for both TE and EE. A comparison was also made of the simple $k$ values calculated using eqn (2) and (3) and accurate $k$ values calculated using eqn (7) and (8) (Fig. 2). The accurate $k$ values were strongly related to their simple counterparts $\left(R^{2}=0.9839\right.$ and 0.9981 for $k_{\mathrm{G}}$ and $k_{\mathrm{P}}$, respectively). However, the former were slightly higher than the latter, especially for $k_{\mathrm{G}}$, according to the slopes of their linear regressions (Fig. 2a), probably due to the degraded parts of starch and phenolics caused by axial mixing in the extruder. To overcome the calculation error, the accurate $k$ values were used as reliable reaction rate constants in this study.

4.1.1. Enzyme concentration. The increase in the extent of gelatinization (GE) was undoubted for enzymatic extrusion because the starch in rice was the direct substrate of amylase (Table 1). The observation of samples $\mathrm{TE}_{\text {control }}, \mathrm{EE}_{\mathrm{EC}-0.5}$ and $\mathrm{EE}_{\text {control }}$ with enzyme dosages ordered from 0 to $1 \%$ (Fig. 1a), showed that the trend of total phenolic content (TPC) retention $\left(c / c_{0}\right)$ coincided with that of GE, which implies that the degradation of starch and phenolics are opposite due to enzyme addition. This contrast was consistent with their kinetic relationship, where the rate constant of GE $\left(k_{\mathrm{G}}\right)$ rose from $1.2 \times$ $10^{-2}$ to $5.5 \times 10^{-2} \mathrm{~s}^{-1}$ while that of TPC $\left(k_{\mathrm{P}}\right)$ dropped from $9.3 \times$ $10^{-3}$ to $2.0 \times 10^{-3} \mathrm{~s}^{-1}$ with increasing EC (Table 3$)$. Compared to TE, lower losses of TPC were found at much lower DP $(\sim 1$ Mpa decrease) and SME ( 70 kJ kg ${ }^{-1}$ decrease) and slightly lower TP $\left(\sim 1.2^{\circ} \mathrm{C}\right.$ decrease $)$ for EE samples. Furthermore, the TPC of bound forms during enzymatic extrusion was high (Table 1), indicating the covalent bond between bound phenolics and structural components such as lignin and structural proteins in the cell wall. ${ }^{40}$ The total antioxidant activity (TAA) represented by DPPH showed a similar upward trend of $\left(c / c_{0}\right)$ but its rate of increase was more mitigated (Fig. 1a), which may be attributed to part of the TAA body consisting of polypeptides, polysaccharides or some Maillard reaction products. ${ }^{\mathbf{1 9 , 4 1}}$

4.1.2. Feed rate. For rice extruded without thermostable $\alpha$ amylase, GE significantly decreased (from 77.0 to $63.5 \%$ ) with the increase in FR (Table 1), while the GE of bio-extruded rice was always at an extremely high level (99.8-99.9\%) with different $F$ applied. As shown in Fig. 1b, both $c / c_{0}$ and TAA increased as $F$ increased 2 -fold. Ozer et $a{ }^{42}$ also reported that increasing $F$ tended to enhance TAA at higher moisture levels. From a dynamic perspective, it is interesting that the $k_{\mathrm{P}}$ of TE increased when more materials were conveyed into the barrel; however, it seems to be opposite to the $c / c_{0}$ of TE. We guess that it is likely to be attributable to the greatly shortened MRT at high $F$ levels. This phenomenon was not found in EE, possibly due to its relative longer MRT compared to that of TE. Besides, it is worth noting that the bound phenolics of bio-extruded rice occupied a larger proportion when $F$ increased, indicating that a mild extrusion environment created with less time and axial mixing might be helpful to phenolic compound retention (Table 1). We did not find similar results for the free/bound

Table 2 Feed rate $(F)$ and screw speed $(N)$ with coded and actual variable levels for the second order factorial central composite experimental design and its responses (high-efficiency enzymatic extrusion)

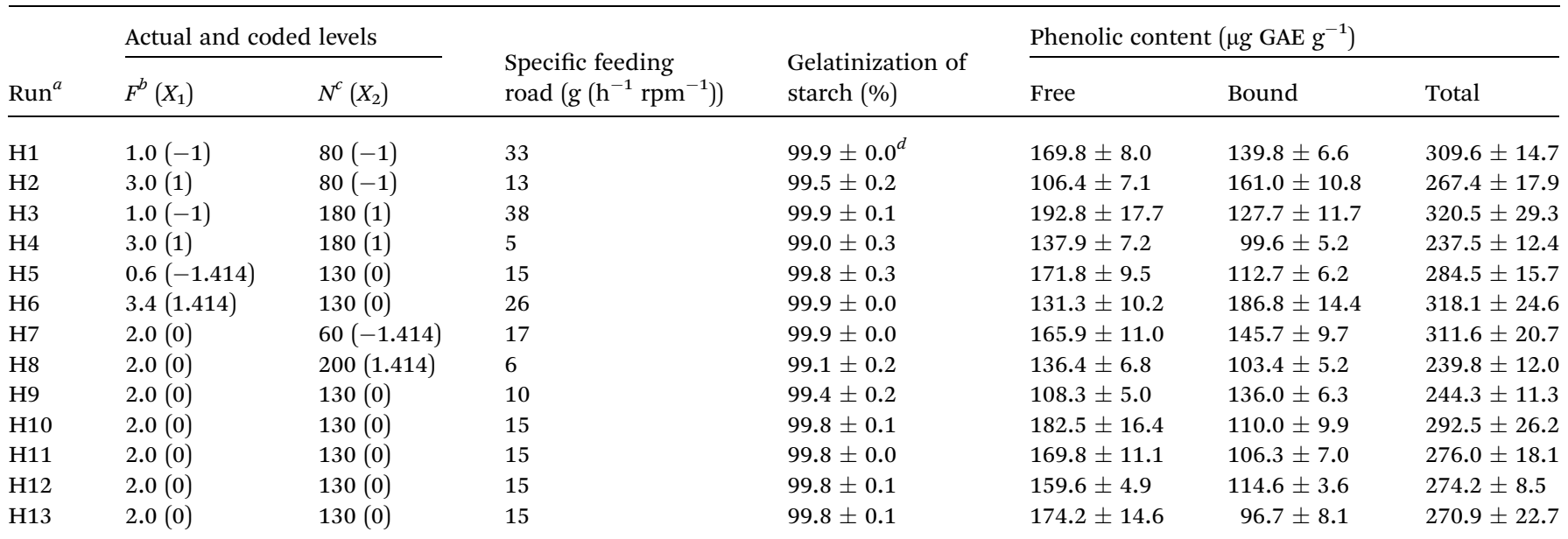

${ }^{a}$ Experimental groups of glutinous rice extruded with thermostable $\alpha$-amylase achieving high enzymatic activity. ${ }^{b} X_{1}$ and $F$, feed rate $\left(\mathrm{kg}\right.$ h $\left.{ }^{-1}\right) .{ }^{c} X_{2}$ and $N$, screw speed (rpm). ${ }^{d}$ Data were expressed as means \pm standard deviations. 


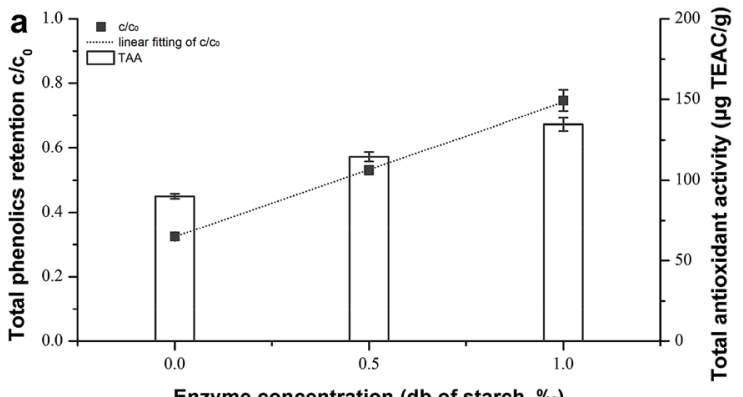

Enzyme concentration (db of starch, \%o)
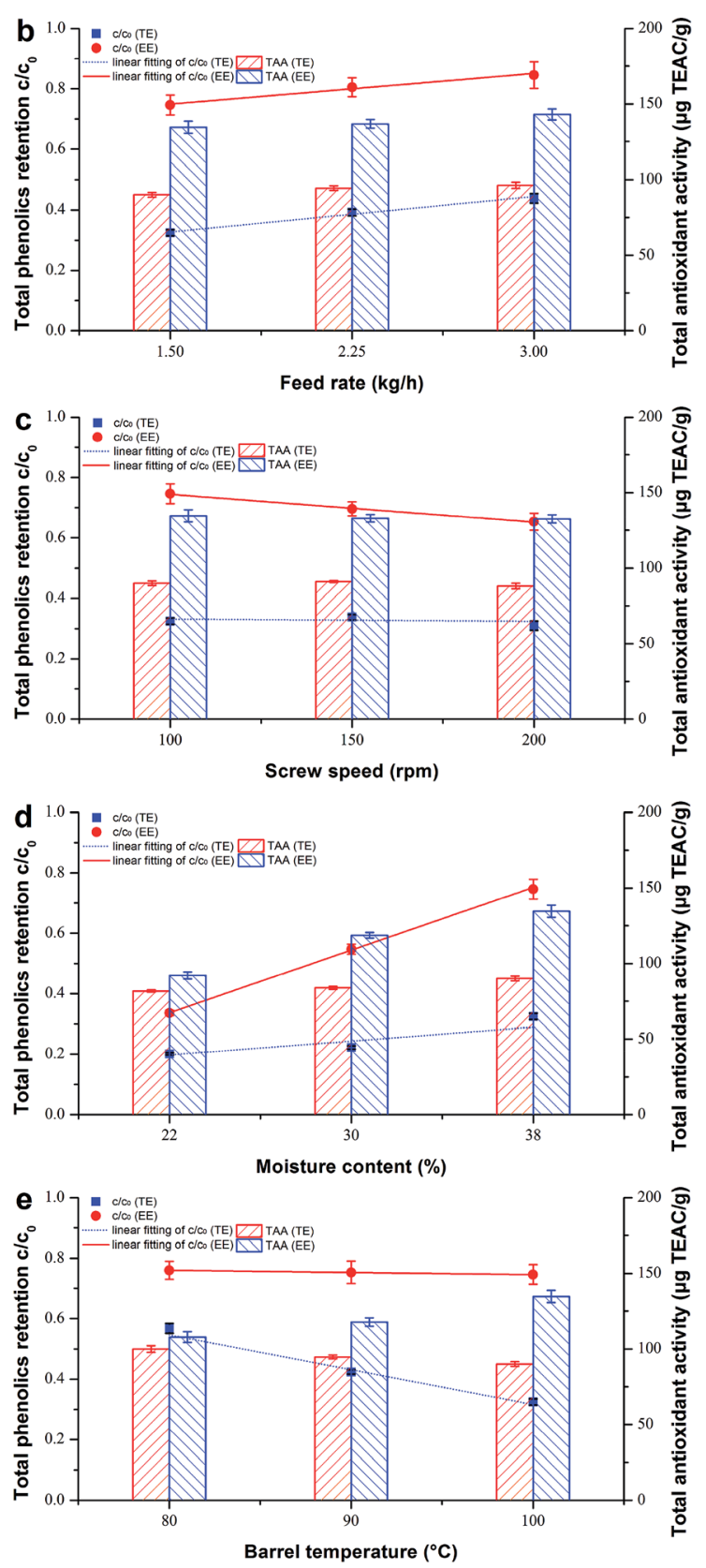

Fig. 1 Comparison of the effect of different operating variables on total phenolics retention $c / c_{0}$ and total antioxidant activity of rice treated by traditional extrusion (TE) and enzymatic extrusion (EE), respectively: (a) enzyme concentration from 0 to $1 \%$, db of starch; (b) feed rate from 1.5 to $3.0 \mathrm{~kg} \mathrm{~h}^{-1}$; (c) screw speed from 100 to $200 \mathrm{rpm}$; (d) moisture content from 22 to $38 \%$, db; (e) barrel temperature from 80 to $100^{\circ} \mathrm{C}$. ratio of phenolics in TE samples and this may be due to their relatively higher PT, SME or friction force impacting on the covalent bonds of insoluble bound phenolics.

4.1.3. Screw speed. GE values slightly increased from 77.0 to $81.4 \%$ with the increase in $N(100-200 \mathrm{rpm})$ for TE samples (Table 1) although the higher $N$ shortened residence time. Similar results of increased GE were previously reported by Cai et al., ${ }^{27}$ who confirmed that shear is a significant contributor to starch gelatinization. The effect of shear stress contrasts to that of MRT for gelatinization, but in this study was somewhat obscure compared to control by $F$. Bhattacharya and Hanna ${ }^{15}$ found that the effect of $N$ was insignificant on starch gelatinization mainly because increasing $N$ lowers the residence time which reduces swelling, making the starch granules less susceptible to shearing action. However, as for EE samples, increased $N$ would make GE decrease (Table 1), indicating that the effect of MRT was stronger than that of the shearing action which was noticeably reduced by starch liquefaction. The enzymatic hydrolysis of rice starch was well conducted as lower DP $(<0.1 \mathrm{Mpa})$ and SME $\left(94.5-181 \mathrm{~kJ} \mathrm{~kg}^{-1}\right)$ were tested for enzymatic extrusion (Table 1). Furthermore, the $k_{\mathrm{G}}$ values of both TE and EE had a positive relation to $N$ (Table 3). Many authors have reported that increasing $N$ would decrease TPC/ TAA significantly for the extrusion of purple-fleshed sweet potato, ${ }^{43}$ green banana flour, ${ }^{44}$ barley-fruit and vegetable byproducts ${ }^{20}$ and other mixtures of cereal flours. ${ }^{42}$ We also found that enzyme addition did not change but deepened the negative connection between $c / c_{0}$ and $N$ (Fig. 3c). Nevertheless, the $k_{\mathrm{P}}$ of $\mathrm{EE}\left(2.0 \times 10^{-3}\right.$ to $\left.3.7 \times 10^{-3} \mathrm{~s}^{-1}\right)$ was still smaller than that of TE $\left(9.3 \times 10^{-3}\right.$ to $\left.1.4 \times 10^{-2} \mathrm{~s}^{-1}\right)$ with the same $N$ (Table 3 ).

Table 3 Degradation rate constants $k_{G}$ and $k_{P}$ as functions of temperature for starch gelatinization and total phenolic content during traditional extrusion (TE) and enzymatic extrusion (EE) according to the initial design in this study

\begin{tabular}{lll}
\hline Sample code & $k_{\mathrm{G}}{ }^{a}\left(\mathrm{~s}^{-1}\right)$ & $k_{\mathrm{P}}{ }^{b}\left(\mathrm{~s}^{-1}\right)$ \\
\hline $\mathrm{TE}_{\text {control }}$ & $1.2 \times 10^{-2} \pm 4.9 \times 10^{-4 c}$ & $9.3 \times 10^{-3} \pm 4.9 \times 10^{-4}$ \\
$\mathrm{TE}_{\mathrm{FR}-2.25}$ & $1.3 \times 10^{-2} \pm 4.4 \times 10^{-4}$ & $8.0 \times 10^{-3} \pm 8.7 \times 10^{-3}$ \\
$\mathrm{TE}_{\mathrm{FR}-3.00}$ & $1.4 \times 10^{-2} \pm 1.2 \times 10^{-3}$ & $1.2 \times 10^{-2} \pm 1.2 \times 10^{-3}$ \\
$\mathrm{TE}_{\mathrm{SS}-150}$ & $1.5 \times 10^{-2} \pm 4.6 \times 10^{-4}$ & $1.0 \times 10^{-2} \pm 4.5 \times 10^{-4}$ \\
$\mathrm{TE}_{\mathrm{SS}-200}$ & $1.7 \times 10^{-2} \pm 6.0 \times 10^{-4}$ & $1.4 \times 10^{-2} \pm 6.8 \times 10^{-4}$ \\
$\mathrm{TE}_{\mathrm{MC}-30}$ & $1.5 \times 10^{-2} \pm 3.6 \times 10^{-4}$ & $1.3 \times 10^{-2} \pm 3.6 \times 10^{-4}$ \\
$\mathrm{TE}_{\mathrm{MC}-22}$ & $2.1 \times 10^{-2} \pm 3.0 \times 10^{-4}$ & $1.5 \times 10^{-2} \pm 3.0 \times 10^{-4}$ \\
$\mathrm{TE}_{\mathrm{BT}-90}$ & $1.1 \times 10^{-2} \pm 2.8 \times 10^{-4}$ & $7.1 \times 10^{-3} \pm 2.8 \times 10^{-4}$ \\
$\mathrm{TE}_{\mathrm{BT}-80}$ & $9.1 \times 10^{-3} \pm 6.3 \times 10^{-4}$ & $4.7 \times 10^{-3} \pm 6.2 \times 10^{-4}$ \\
$\mathrm{EE}_{\mathrm{control}}$ & $5.5 \times 10^{-2} \pm 6.0 \times 10^{-4}$ & $2.0 \times 10^{-3} \pm 4.6 \times 10^{-4}$ \\
$\mathrm{EE}_{\mathrm{EC}-0.5}$ & $4.5 \times 10^{-2} \pm 3.9 \times 10^{-4}$ & $4.7 \times 10^{-3} \pm 3.3 \times 10^{-4}$ \\
$\mathrm{EE}_{\mathrm{FR}-2.25}$ & $6.4 \times 10^{-2} \pm 5.3 \times 10^{-4}$ & $1.7 \times 10^{-3} \pm 4.2 \times 10^{-4}$ \\
$\mathrm{EE}_{\mathrm{FR}-3.00}$ & $7.7 \times 10^{-2} \pm 7.7 \times 10^{-4}$ & $1.6 \times 10^{-3} \pm 6.3 \times 10^{-4}$ \\
$\mathrm{EE}_{\mathrm{SS}-150}$ & $6.0 \times 10^{-2} \pm 5.1 \times 10^{-4}$ & $2.8 \times 10^{-3} \pm 3.8 \times 10^{-4}$ \\
$\mathrm{EE}_{\mathrm{SS}-200}$ & $6.5 \times 10^{-2} \pm 6.7 \times 10^{-4}$ & $3.7 \times 10^{-3} \pm 5.2 \times 10^{-4}$ \\
$\mathrm{EE}_{\mathrm{MC}-30}$ & $3.4 \times 10^{-2} \pm 4.0 \times 10^{-4}$ & $4.6 \times 10^{-3} \pm 3.5 \times 10^{-4}$ \\
$\mathrm{EE}_{\mathrm{MC}-22}$ & $2.9 \times 10^{-2} \pm 4.2 \times 10^{-4}$ & $5.3 \times 10^{-3} \pm 3.9 \times 10^{-4}$ \\
$\mathrm{EE}_{\mathrm{BT}-90}$ & $5.4 \times 10^{-2} \pm 6.6 \times 10^{-4}$ & $2.0 \times 10^{-3} \pm 5.2 \times 10^{-4}$ \\
$\mathrm{EE}_{\mathrm{BT}-80}$ & $4.7 \times 10^{-2} \pm 5.2 \times 10^{-4}$ & $2.0 \times 10^{-3} \pm 4.3 \times 10^{-4}$ \\
${ }_{\mathrm{D}}$ &
\end{tabular}

${ }^{a}$ Degradation rate constant of rice starch. ${ }^{b}$ Destruction rate constant of total phenolic content in rice. ${ }^{c}$ Data were expressed as means \pm standard deviations. 

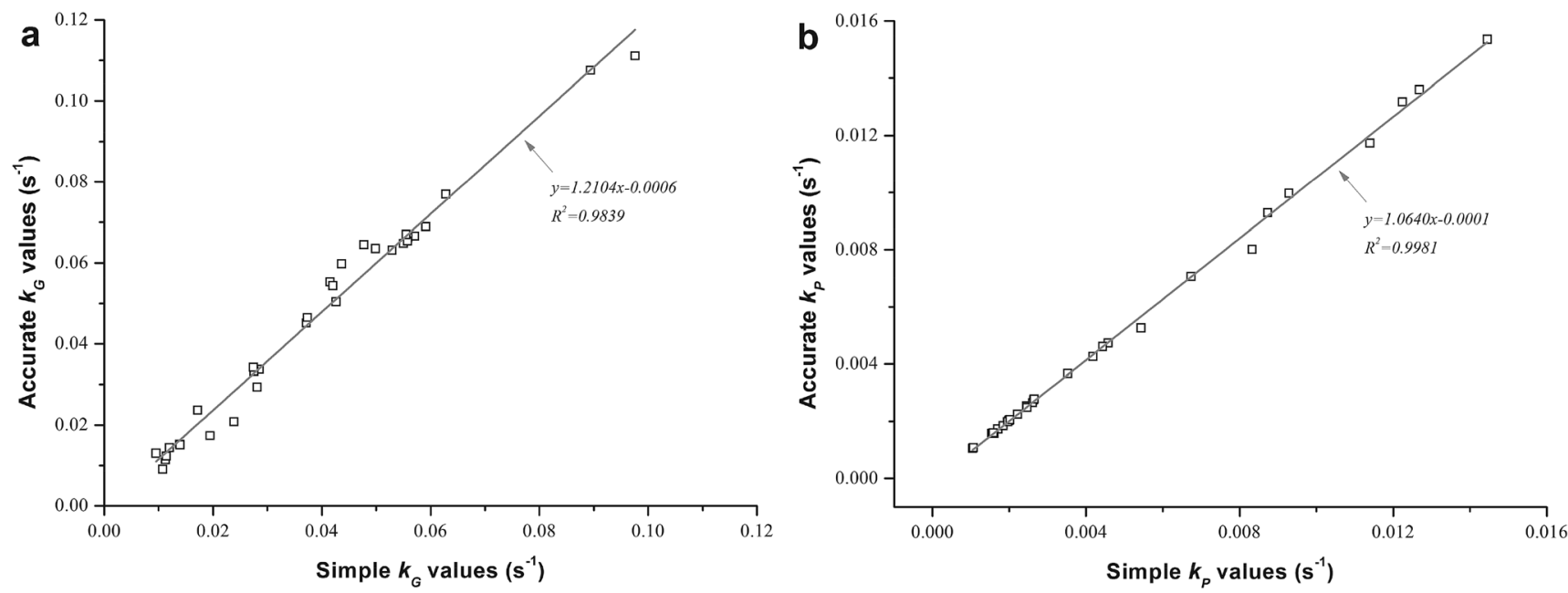

Fig. 2 Accurate $k_{\mathrm{G}}$ and $k_{\mathrm{P}}$ values calculated for (a) extent of starch gelatinization and (b) total phenolics destruction, respectively, as related to their simple values.

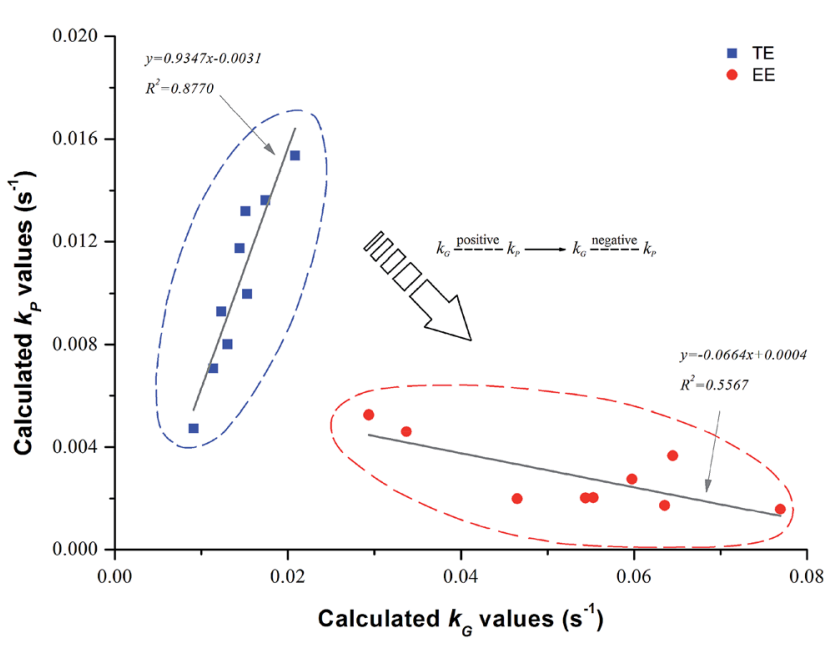

Fig. 3 The relationship between calculated $k_{G}$ and $k_{P}$ during traditional extrusion (TE) and enzymatic extrusion (EE).
4.1.4. Moisture content. $M$ is a special factor not only for starch swelling and gelatinization but also for the activation of thermostable $\alpha$-amylase during bio-extrusion. As for starch gelatinization of TE samples, GE significantly decreased with increasing $M$ (Table 1), and this agreed with the results of Cai et al. ${ }^{27}$ This may be attributed to the increase in viscosity and mechanical energy dissipation at lower $M$ levels resulting in increased mechanical shear stress and therefore increasing GE. When the enzyme was introduced, the reaction went in exactly the opposite direction against TE because more water was good for amylase to attack the starch substrate, and this was consistent with their kinetic constants $k_{\mathrm{G}}$, as shown in Table 3 . Although less water would only spoil the effect of enzymatic hydrolysis, the TPC of EE $(122.3 \mu \mathrm{g}$ $\left.\mathrm{GAE}^{-1}\right)$ was still higher than that of TE $\left(73.2 \mu \mathrm{g} \mathrm{GAE}^{-1}\right)$ at the lowest $M$ level of $22 \%$ (Table 1 ). Hence, there was no doubt that the $c / c_{0}$ and TAA of EE samples increased with increasing $M$ up to 38\% (Fig. 1d), probably due to the milder extrusion environment where PT, DP and SME all decreased markedly (Table 1). For traditional extrusion without enzyme, $c / c_{0}$ also slightly increased with the increase in $M$. Nevertheless, many researchers reported that TPC

Table 4 Correlation coefficients amongst processing parameters and responsive values for traditional extrusion (TE) and enzymatic extrusion (EE) of rice ra,b $^{a}$

\begin{tabular}{|c|c|c|c|c|c|c|c|c|c|}
\hline & $\mathrm{PT}$ & DP & SME & SFL & MRT & $\mathrm{Pe}$ & GE & $c / c_{0}$ & TAA \\
\hline PT & 1.000 & 0.286 & 0.394 & 0.000 & -0.304 & -0.019 & 0.121 & -0.441 & -0.072 \\
\hline DP & & 1.000 & $0.875 * *$ & 0.012 & -0.236 & 0.442 & -0.246 & $-0.676^{* *}$ & $-0.647^{* *}$ \\
\hline SFL & & & & 1.000 & -0.395 & $0.823 * *$ & -0.183 & 0.233 & 0.157 \\
\hline MRT & & & & & 1.000 & -0.235 & $0.566^{*}$ & 0.431 & 0.371 \\
\hline $\mathrm{Pe}$ & & & & & & 1.000 & 0.273 & 0.066 & -0.186 \\
\hline TAA & & & & & & & & & 1.000 \\
\hline
\end{tabular}

${ }^{a}$ PT, DP, SME, SFL, MRT, Pe, GE, $c / c_{0}$ and TAA represent product temperature, die pressure, special mechanical energy, specific feeding road, mean residence time, Peclet number, extent of gelatinization, retention ratio of total phenolic content and total antioxidant activity, respectively. ${ }^{b}{ }^{*} p<$ $0.05 ;{ }^{*} p<0.01 ;{ }^{* *} p<0.001$. 

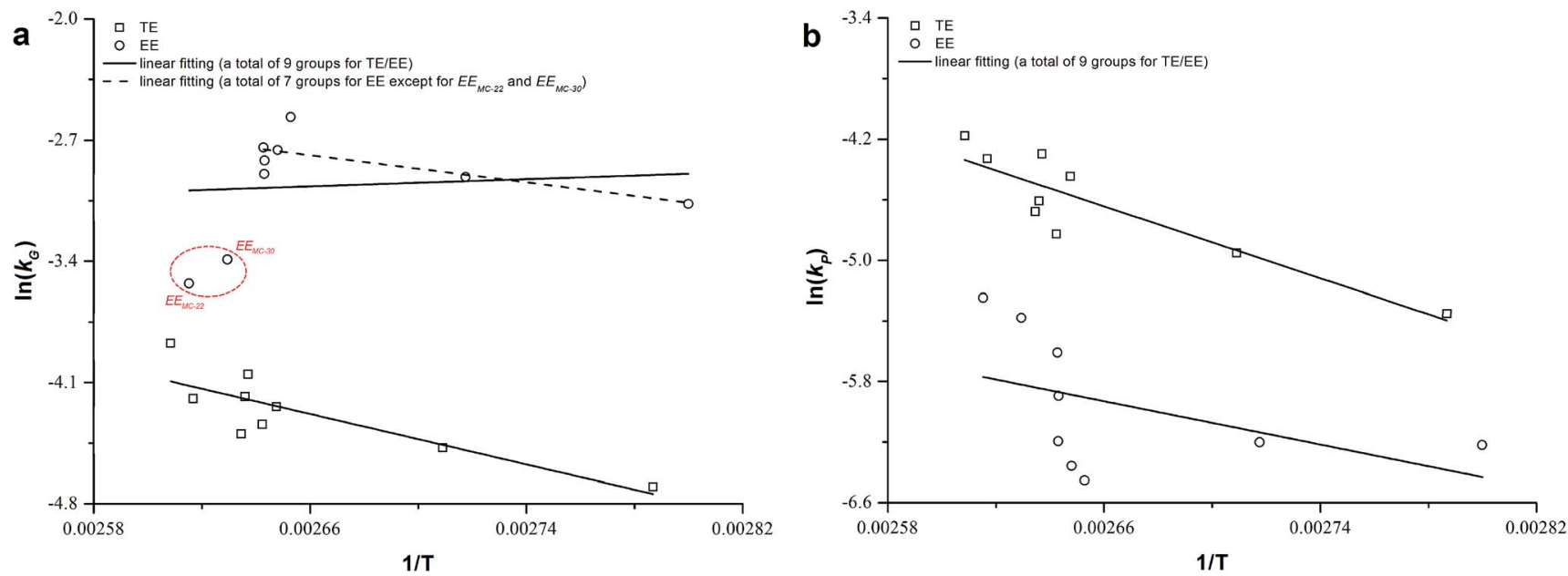

Fig. 4 Comparison of traditional extrusion (TE) and enzymatic extrusion (EE) as Arrhenius plots of effects of product temperature on the rate constants $k_{\mathrm{G}}$ and $k_{\mathrm{P}}$ of starch gelatinization (GE) and total phenolic content (TPC).

was almost destroyed when more water was added ${ }^{42,43,45}$ resulting from the polymerization of phenolics under higher water levels. Interestingly, we found that even the highest $M$ level $(<20 \%)$ used in their experiments was lower than the lowest level $(22 \%)$ used in this study, so we guess that when $M$ exceeded a certain limit, the possibility of TPC retention caused by decreased shearing force, local friction and SME may be stronger than the tendency of phenolic polymerization.
4.1.5. Barrel temperature. $T$ is another special factor influencing bio-extrusion directly and tremendously. The enzyme can express its activity only over a relatively narrow range of temperature, so a $T$ of $80-100{ }^{\circ} \mathrm{C}$ was set to investigate the kinetics during enzymatic extrusion in this study. It was inevitable that GE increased with the increase in $T$, especially for the rice extruded with thermostable $\alpha$-amylase (Table 1). As for the TE samples, some phenolics were very sensitive to temperature and TPC decreased with rising temperature

Table 5 Results of various models for starch gelatinization and phenolics loss during traditional extrusion (TE) and enzymatic extrusion (EE) based on the initial design in this study

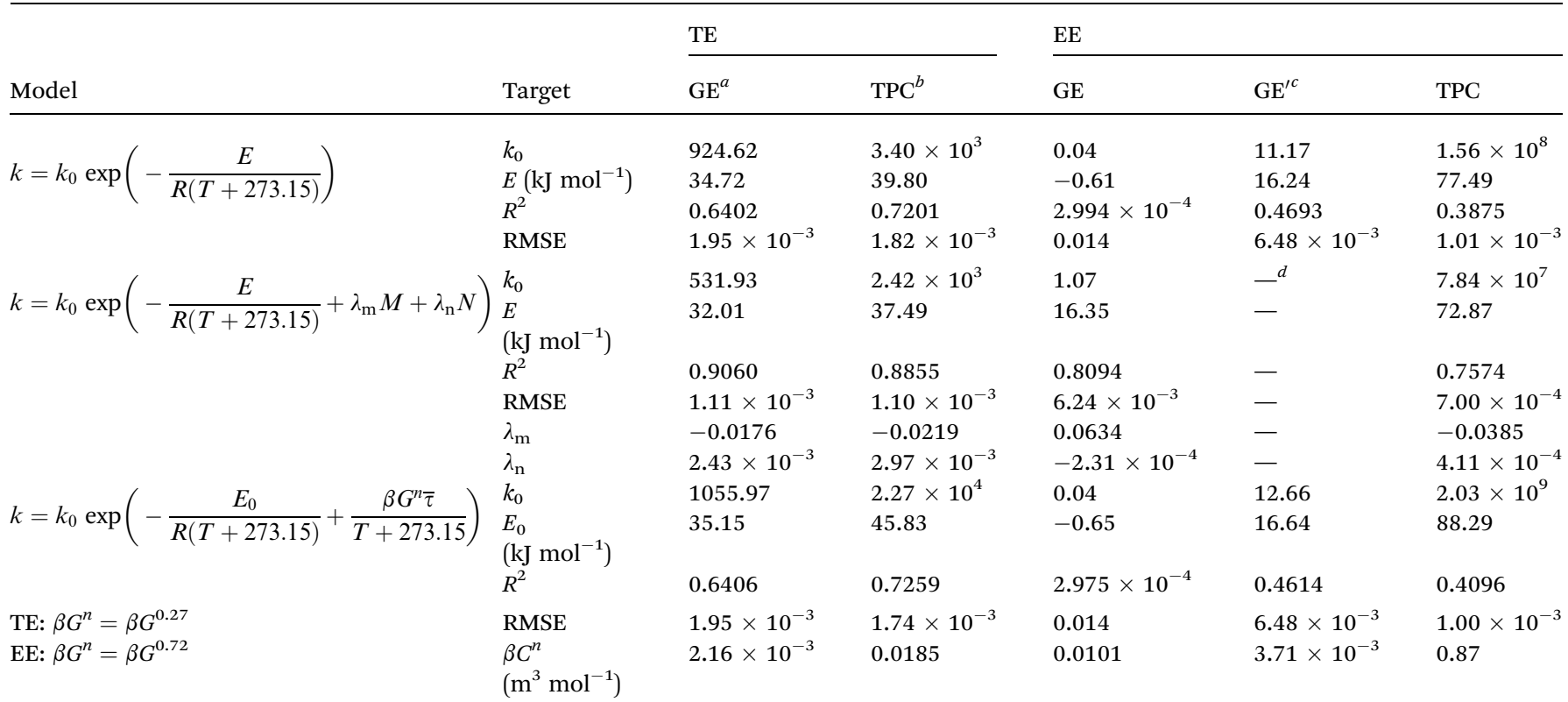

${ }^{a} \mathrm{GE}$, extent of gelatinization. ${ }^{b} \mathrm{TPC}$, total phenolic content (in destruction). ${ }^{c} \mathrm{GE}^{\prime}$, extent of gelatinization for enzymatic extruded rice except for samples coded as $\mathrm{EE}_{\mathrm{MC}-22}$ and $\mathrm{EE}_{\mathrm{MC}-30}$ (these two samples are processed without high or certain enzymatic hydrolysis for rice starch though thermostable $\alpha$-amylase were both added). The errors in calculating the targets in the models were made mathematically when $\mathrm{EE}_{\mathrm{MC}-22}$ and $\mathrm{EE}_{\mathrm{MC}-30}$ were included. ${ }^{d}$ Considering the calculation was conducted without $\mathrm{EE}_{\mathrm{MC}-22}$ and $\mathrm{EE}_{\mathrm{MC}-30}$, the second model with variable $M$ (moisture content) in this table was meaningless and was not detected. 


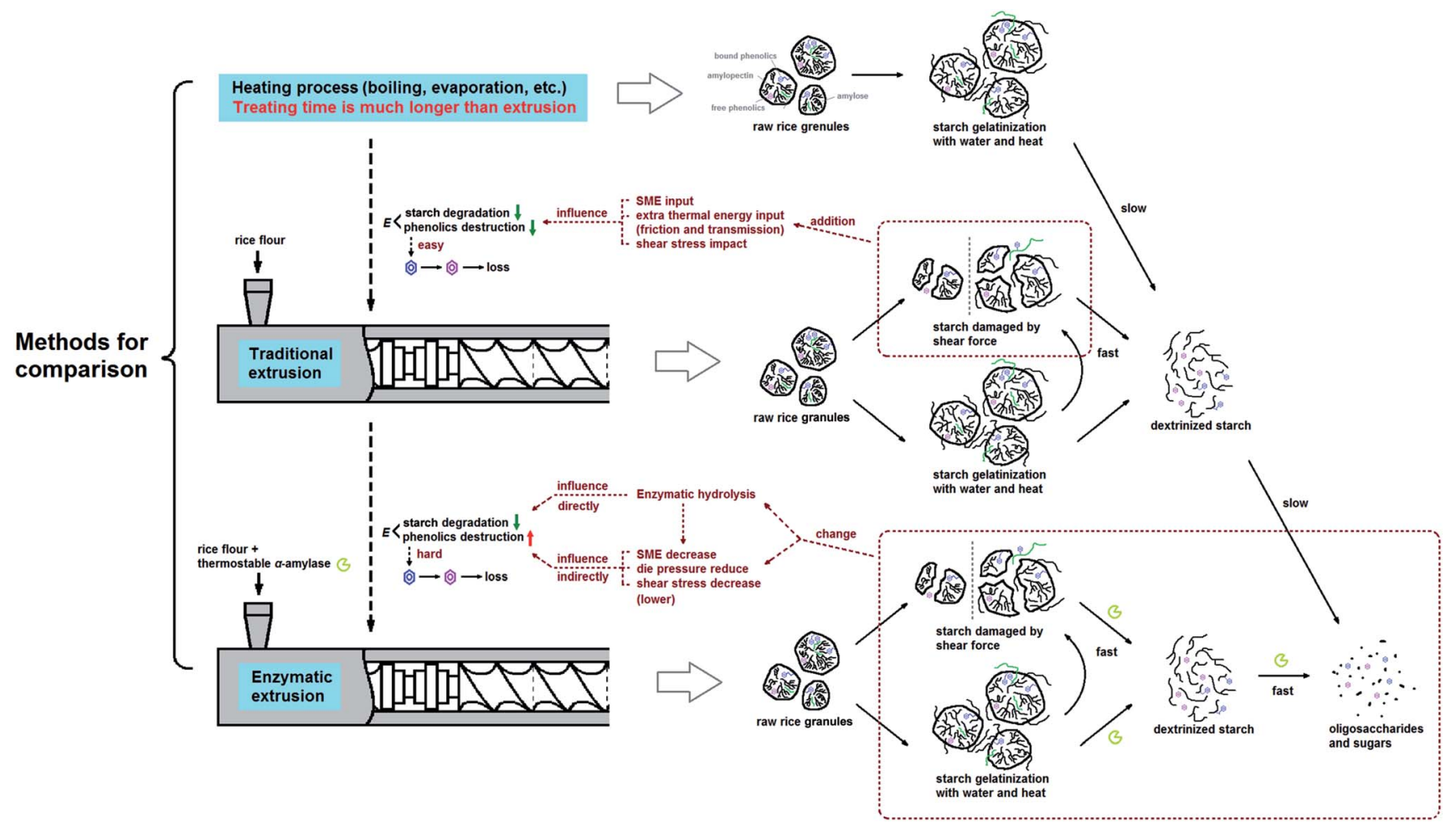

Fig. 5 Schematic flow of total phenolics retention of glutinous rice flour related to starch gelatinization and degradation during enzymatic extrusion (speculation based on the change of active energy E). (Heating process, traditional extrusion and enzymatic extrusion were discussed in the same temperature conditions).

(Fig. 1e). Similar results were reported previously. ${ }^{18,45}$ However, the trend in TPC destruction was slowed down for the EE samples, probably because the increased heat impact on phenolics was offset to some extent by the enhanced indirect protection of starch liquefaction on phenolics. By contrast, the TAA of the EE samples increased due to the generation of other antioxidants such as Maillard reaction products under higher temperature, and this agreed with previous observations. ${ }^{19,37}$

4.1.6. Relationship between $\boldsymbol{k}_{\mathrm{G}}$ and $\boldsymbol{k}_{\mathrm{P}}$. The $k_{\mathrm{P}}$ was strongly and positively related to $k_{\mathrm{G}}$ during traditional extrusion, while it was negatively related to $k_{\mathrm{G}}$ during enzymatic extrusion (Fig. 3). This indicates that the more severe reaction environment of the extrusion process (without enzyme) combined with the greater thermomechanical energy input, local friction and shearing action accelerate the degradation of starch and the loss of TPC simultaneously. The inverted relationship between $k_{\mathrm{G}}$ and $k_{\mathrm{P}}$ was caused by the introduction of thermostable $\alpha$-amylase, which forces the starch substrate to degrade and then changes the original intensity of the extrusion process. Van der Veen et al. ${ }^{46}$ reported that thermostable $\alpha$-amylase might be flexible and allow a certain alignment in the shear field, making itself less sensitive to the shear forces. This self-defense mechanism of an enzyme may also benefit the retention of small molecules such as phenolic compounds, while it is noticeable that the modification of enzyme addition depends on its activity during extrusion and therefore the negative connection between the $k_{\mathrm{G}}$ and $k_{\mathrm{P}}$ of the EE samples was not very obvious $\left(R^{2}=0.5567\right)$, as shown in the red circles of Fig. 3 . In addition, the correlation analysis based on TE/EE showed that the $c / c_{0}$ as well as the TAA were significantly and negatively related to DP $(R=-0.676, p<0.01)$ and SME $(R=-0.713, p<0.01)$ (Table $4)$. Nevertheless, it was not as expected that there was no significant relationship between MRT and $c / c_{0}$, implying that the great decrease in DP and SME caused by the enzyme was very crucial for traditional extrusion, which may lead to a change in MRT reducing the TPC loss, as was found here.

Table 6 Degradation rate constants $k_{\mathrm{G}}$ and $k_{\mathrm{P}}$ as functions of temperature for starch gelatinization and total phenolic content during traditional extrusion (TE) and enzymatic extrusion (EE) according to the second order factorial central composite experimental design

\begin{tabular}{lll}
\hline Run & $k_{\mathrm{G}}{ }^{a}\left(\mathrm{~s}^{-1}\right)$ & $k_{\mathrm{P}}{ }^{b}\left(\mathrm{~s}^{-1}\right)$ \\
\hline H1 & $5.0 \times 10^{-2} \pm 3.6 \times 10^{-4 c}$ & $1.1 \times 10^{-3} \pm 3.1 \times 10^{-4}$ \\
H2 & $3.3 \times 10^{-2} \pm 4.2 \times 10^{-4}$ & $1.6 \times 10^{-3} \pm 3.4 \times 10^{-4}$ \\
H3 & $6.7 \times 10^{-2} \pm 8.2 \times 10^{-4}$ & $1.1 \times 10^{-3} \pm 7.1 \times 10^{-4}$ \\
H4 & $2.4 \times 10^{-2} \pm 2.4 \times 10^{-4}$ & $1.6 \times 10^{-3} \pm 1.8 \times 10^{-4}$ \\
H5 & $6.5 \times 10^{-2} \pm 6.0 \times 10^{-4}$ & $2.3 \times 10^{-3} \pm 5.2 \times 10^{-4}$ \\
H6 & $1.1 \times 10^{-1} \pm 1.2 \times 10^{-3}$ & $1.9 \times 10^{-3} \pm 1.1 \times 10^{-3}$ \\
H7 & $1.1 \times 10^{-1} \pm 1.1 \times 10^{-3}$ & $2.0 \times 10^{-3} \pm 9.1 \times 10^{-4}$ \\
H8 & $3.4 \times 10^{-2} \pm 3.9 \times 10^{-4}$ & $2.5 \times 10^{-3} \pm 3.3 \times 10^{-4}$ \\
H9 & $6.3 \times 10^{-2} \pm 7.0 \times 10^{-4}$ & $4.3 \times 10^{-3} \pm 6.0 \times 10^{-4}$ \\
H10 & $6.6 \times 10^{-2} \pm 9.7 \times 10^{-4}$ & $2.1 \times 10^{-3} \pm 8.4 \times 10^{-4}$ \\
H11 & $6.9 \times 10^{-2} \pm 7.4 \times 10^{-4}$ & $2.7 \times 10^{-3} \pm 6.5 \times 10^{-4}$ \\
H12 & $6.5 \times 10^{-2} \pm 3.4 \times 10^{-4}$ & $2.5 \times 10^{-3} \pm 2.9 \times 10^{-4}$ \\
H13 & $6.7 \times 10^{-2} \pm 9.2 \times 10^{-4}$ & $2.8 \times 10^{-3} \pm 8.0 \times 10^{-4}$ \\
\end{tabular}

${ }^{a}$ Degradation rate constant of rice starch. ${ }^{b}$ Destruction rate constant of total phenolic content in rice. ${ }^{c}$ Data were expressed as means \pm standard deviations. 
Table 7 Prediction equations of second-order regression for response values ${ }^{a}$

\section{Regression parameter coefficients}

\begin{tabular}{llll}
\hline & \multicolumn{2}{l}{ Regression parameter coefficients } \\
\cline { 2 - 4 } & & & \\
\cline { 2 - 4 } Parameters & GE $(\%)$ & $c / c_{0}(\%)$ & TAA $(\mu \mathrm{g}$ \\
\hline TEAC $\left.\mathrm{g}^{-1}\right)$
\end{tabular}

\subsection{Kinetic models for starch gelatinization and phenolic destruction of TE/EE}

Considering a nearly constant temperature profile along the screw channel in the extrusion cooking zones, the relation of $k_{\mathrm{G}}$ and $k_{\mathrm{P}}$ to actual temperature was modeled using eqn (9). The Arrhenius plots of TE/EE with different levels of operating parameters were developed (Fig. 4). For traditional extrusion, a $34.72 \mathrm{~kJ} \mathrm{~mol}^{-1}$ activation energy $(E)$ was obtained for starch gelatinization. That is close to the results from Wang et al., ${ }^{47}$ who reported an $E$ of $9.6 \mathrm{kcal} \mathrm{mol}^{-1}$ for rough rice treated at 85$120{ }^{\circ} \mathrm{C}$ and $>45 \%$ water. However, the $E$ of starch gelatinization for rice extruded with enzyme was abnormal $\left(-0.61 \mathrm{~kJ} \mathrm{~mol}^{-1}\right)$ with an extremely low confidence level $\left(R^{2}=2.994 \times 10^{-4}\right)$ (Table 5) and the slope of the linear fit between $1 / T$ and $\ln \left(k_{\mathrm{G}}\right)$ was unexpectedly positive (Fig. 4a). These calculation errors may be due to the presence of samples $\mathrm{EE}_{\mathrm{MC}-30}$ and $\mathrm{EE}_{\mathrm{MC}-22}$ (red circle in Fig. 4a), for which the added enzyme would be inactivated at low $M$ level and starch could not be rapidly gelatinized as in traditional extrusion. Ignoring these two samples, a relatively normal $E$ of $16.24 \mathrm{~kJ} \mathrm{~mol}^{-1}$ was obtained, but the confidence of this result was still not too high $\left(R^{2}=0.4693\right)$ possibly because the temperature or other conditions of some $\mathrm{EE}$ samples in the rest of the 7 groups were unfriendly to the enzyme (Table 5). As for TPC destruction, the indirect protection of enzyme addition to phenolics could be explained by the increase in $E$ values from 39.80 to $77.49 \mathrm{~kJ} \mathrm{~mol}^{-1}$. Guzman-tello and Cheftel $^{31}$ reported that the $E$ values of thiamine destruction decreased from 93.9 to $49.9 \mathrm{~kJ} \mathrm{~mol}^{-1}$ when extrusion cooking was applied instead of batch heating. This implies that although extrusion of starch-based materials provided more thermomechanical energy and physical action to decrease the $E$ of some small molecules compared to other heating processes, it can be indirectly reversed by the introduction of an enzyme under appropriate conditions. Based on this, we inferred and
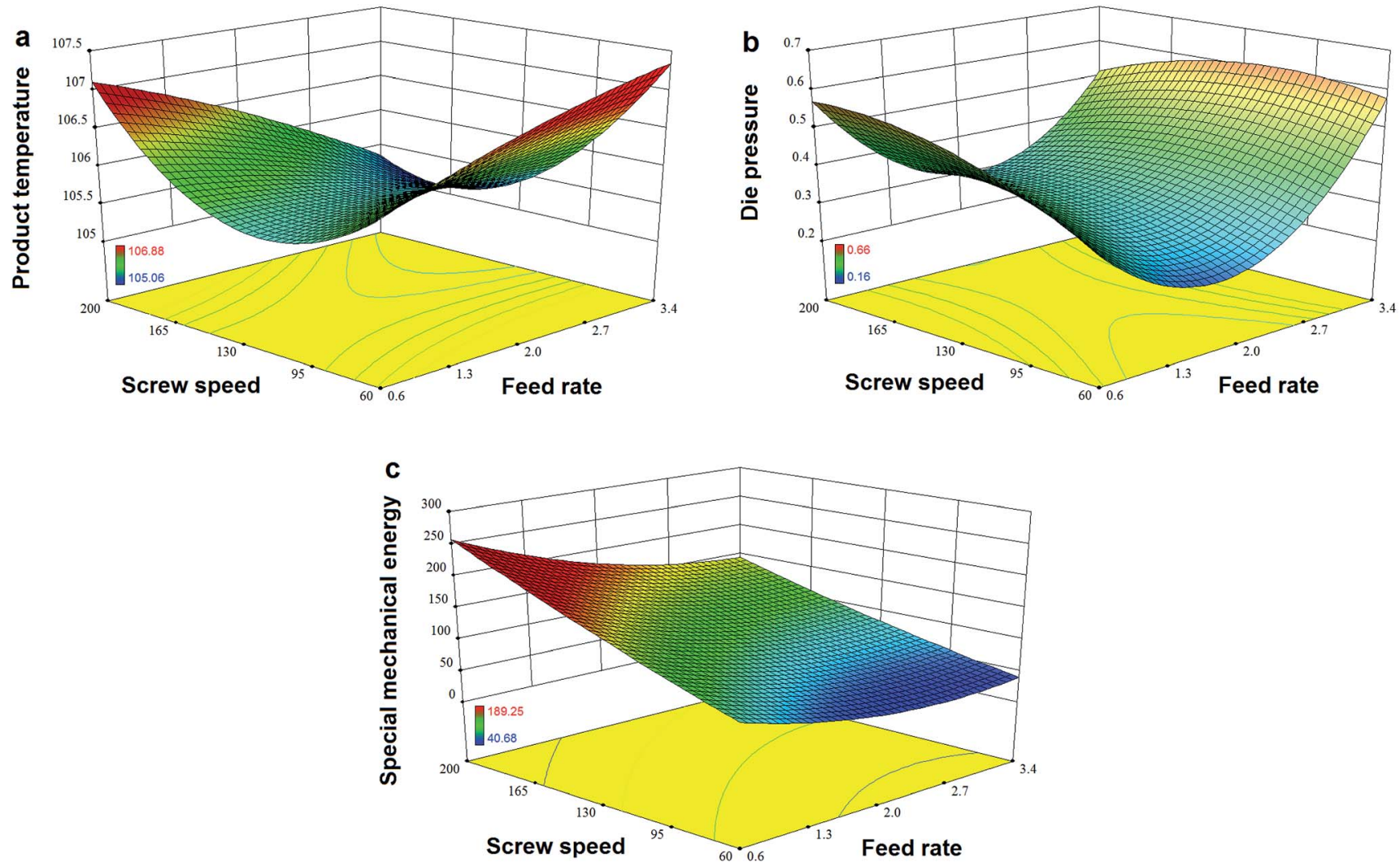

Fig. 6 Effects of feed rate and screw speed on processing parameters (a) product temperature, (b) die pressure and (c) special mechanical energy for high-efficiency enzymatic extrusion. 
summarized the mechanism of phenolic retention related to starch gelatinization of rice extruded with thermostable $\alpha$ amylase by comparison with traditional extrusion or other heating processes in statistics and kinetics (Fig. 5). The change in $E$ for reactions was the key factor for explaining the TPC retention in the complex system of bio-extrusion.

Actually, operating parameters such as $F, N$ and $M$ could also influence the $E$ of GE and TPC degradation. Among these, the effect of $F$ on $k_{\mathrm{P}}$ was not relatively significant for TE samples (Table 3 ) and thus, we fitted the calculated $k_{\mathrm{G}}$ and $k_{\mathrm{P}}$ values as a function of temperature, moisture and screw speed using eqn (10). Similar fitting was conducted by Ilo and Berghofer, ${ }^{32}$ who found that increased FR decreased thiamin destruction $(p<$ 0.05 ) but did not affect its $k$ values. For traditional extrusion, the $E$ values of both starch gelatinization $\left(E: 32.01 \mathrm{~kJ} \mathrm{~mol}^{-1}\right)$ and TPC ( $E: 37.49 \mathrm{~kJ} \mathrm{~mol}^{-1}$ ) destruction made no difference to those found in the Arrhenius model of eqn (9) (Table 5), and this result corresponded with other reports on other food ingredients. $^{30,32}$ Surprisingly, the fitting for GE during enzymatic extrusion succeeded $\left(R^{2}=0.8094, \mathrm{RMSE}=0.0062\right)$ using the revised Arrhenius model, i.e., eqn (10), where $M$ and $N$ were added as corrective terms. The combined influence of $M$ on starch gelatinization and enzymatic hydrolysis was optimized in calculation, and an $E$ of $16.35 \mathrm{~kJ} \mathrm{~mol}^{-1}$ was achieved, $\sim 2$ times less than that of traditional extrusion of rice. A more precise $E$ value $\left(72.87 \mathrm{~kJ} \mathrm{~mol}^{-1}\right)$ was also obtained mathematically for
TPC destruction during bio-extrusion $\left(R^{2}=0.7574\right)$ when the effects of $M$ and $N$ were considered.

The breakdown of starch granules and phenolics in extrusion with/without enzyme addition may be affected by mechanical shear stress in the cooking barrel. Eqn (12) was used to model the combined effect of temperature and shear stress on GE and TPC. The effect of shear stress on enzyme activation with high $E\left(240 \mathrm{~kJ} \mathrm{~mol}^{-1}\right)$ could be neglected for modeling because hardly any enzyme inactivation occurred when a shear stress lower than $\sim 25 \mathrm{kPa}$ was applied. ${ }^{46}$ The constant $G$ in eqn (12) was unknown and was combined with $\beta$ for modeling. Considering the huge differences in the physical and rheological properties of TE and EE samples, we used different coefficients to calculate the apparent viscosity (for gaining $\bar{\tau}$ subsequently) using the following equations, respectively:

$$
\begin{aligned}
& \text { TE }: \quad \eta=17.43 \gamma^{-0.73} \exp \left(\frac{2558}{T}-0.0094 M\right) \\
& \mathrm{EE}: \quad \eta=755.05 \gamma^{-0.28} \exp \left(\frac{3.73}{T}-0.0716 M\right)
\end{aligned}
$$

The $E_{0}$ representing the activation energy in a shear-less environment approached the $E$ calculated by the Arrhenius model for starch gelatinization during enzymatic extrusion
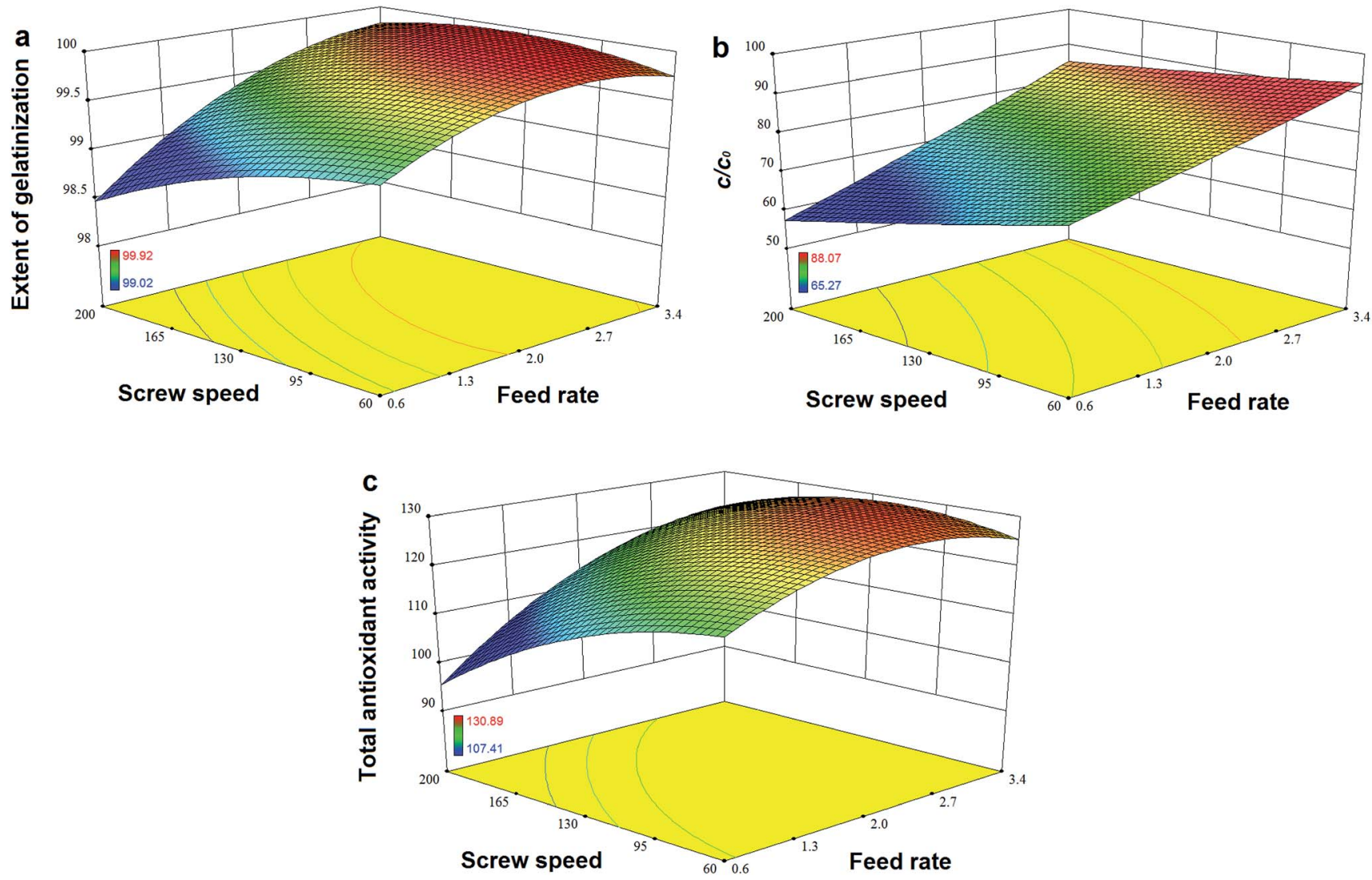

Fig. 7 Effects of feed rate and screw speed on response values (a) extent of gelatinization, (b) retention ratio of total phenolic content $c / c_{0}$ and (c) total antioxidant activity for high-efficiency enzymatic extrusion. 
(Table 5). However, its $R^{2}$ was not high, which was also found for the TPC destruction of the EE samples $\left(R^{2}=0.4096\right)$. Hence, modeling the reaction kinetics of extruded starch-based material can be a challenge when enzymatic hydrolysis performs well and the changes in reaction tendency are complex. The comparison of the coefficients of $R^{2}$ and RMSE demonstrated that the revised model of temperature, moisture and screw speed (eqn (10)) was better than the revised model of temperature and shear stress (eqn (12)) in this study. As previously reported, ${ }^{32}$ the kinetic model including shear stress was empirically predicted and did not adequately reflect the true reaction mechanism during extrusion.

\subsection{RSM for high-efficiency enzymatic extrusion}

High-efficiency enzymatic extrusion was obtained for RSM as all 13 groups achieved a GE of over 99\% (Table 2). Table 6 shows that the $k_{\mathrm{G}}$ ranging from $2.37 \times 10^{-2}$ to $1.11 \times 10^{-3}$ were a magnitude greater than $k_{\mathrm{P}}$ (from $1.05 \times 10^{-3}$ to $4.26 \times 10^{-3}$ ). The undesirable irreversible denaturing of $\alpha$-amylase $(<13 \%$ except for H5) was negligible for complex modeling based on its high residual enzyme activity (data not shown) after extrusion.

The second-order regression equations fitted for response values of $\mathrm{GE}, c / c_{0}$, and TAA were as follows:

$$
\begin{aligned}
& \mathrm{GE}=99.00+0.61 F+9.16 \times 10^{-4} N+2.36 \times 10^{-3} F N \\
&-0.15 F^{2}-3.26 \times 10^{-5} N^{2} \\
& c / c_{0}=80.62+3.83 F-0.15 N+0.03 F N+0.26 F^{2} \\
&+5.77 \times 10^{-5} N^{2}
\end{aligned}
$$

$\mathrm{TAA}=111.88+11.46 F+0.05 N+0.05 F N-3.07 F^{2}$

$$
-9.48 \times 10^{-4} N^{2}
$$

The linear terms of $F$ and $N$ for all GE, $c / c_{0}$, and TAA were significant $(p<0.001$ or $p<0.01)$ (Table 7). Changes in GE were negatively linked to the quadratic terms of both $F(p<0.001)$ and $N(p<0.01)$. There was a positive interaction term of these two independent variables for GE, while no quadratic or interaction terms were found to contribute to $c / c_{0}$. In brief, the regression models on GE, $c / c_{0}$, and TAA all expressed good fits with high $R^{2}$ (0.9848, 0.9185 and 0.9051 , respectively) and significant $p$ values $(<0.0001,0.0011$ and 0.0018 , respectively) for highefficiency enzymatic extrusion.

Fig. 7a and $b$ show that TPC retention as well as GE increased with a decrease in $N$ and an increase in $F$, and this was close to the observation in the experiments for the initial design. The same trends in the influence of $F$ and $N$ on TAA

\begin{tabular}{|c|c|c|c|c|c|c|c|c|c|}
\hline & $\mathrm{PT}$ & $\mathrm{DP}$ & SME & SFL & MRT & $\mathrm{Pe}$ & GE & $c / c_{0}$ & TAA \\
\hline PT & 1.000 & -0.098 & -0.113 & 0.339 & 0.281 & 0.189 & -0.223 & -0.061 & -0.172 \\
\hline DP & & 1.000 & 0.268 & -0.002 & 0.193 & -0.102 & -0.184 & 0.024 & -0.610 \\
\hline SFL & & & & 1.000 & -0.380 & $0.914 * *$ & $0.723 * *$ & $0.868 * * *$ & $0.688^{* *}$ \\
\hline MRT & & & & & 1.000 & $-0.555^{*}$ & $-0.737^{* *}$ & $-0.564^{*}$ & $-0.600^{*}$ \\
\hline $\mathrm{Pe}$ & & & & & & 1.000 & $0.816^{* *}$ & $0.787^{* *}$ & $0.844^{* * *}$ \\
\hline TAA & & & & & & & & & 1.000 \\
\hline
\end{tabular}
were found (Fig. 7c), which was similar to the results previously reported. ${ }^{42}$ At a high level of $F$, GE slightly decreased

Table 8 Correlation coefficients amongst processing parameters and responsive values for rice extruded with thermostable $\alpha$-amylase achieving high enzymatic activity ${ }^{a, b}$

${ }^{a}$ PT, DP, SME, SFL, MRT, Pe, GE, $c / c_{0}$ and TAA represent product temperature, die pressure, special mechanical energy, specific feeding road, mean residence time, Peclet number, extent of gelatinization, retention ratio of total phenolic content and total antioxidant activity, respectively. ${ }^{b}{ }^{*} p<$ $0.05 ; * * p<0.01 ; * * *<0.001$.
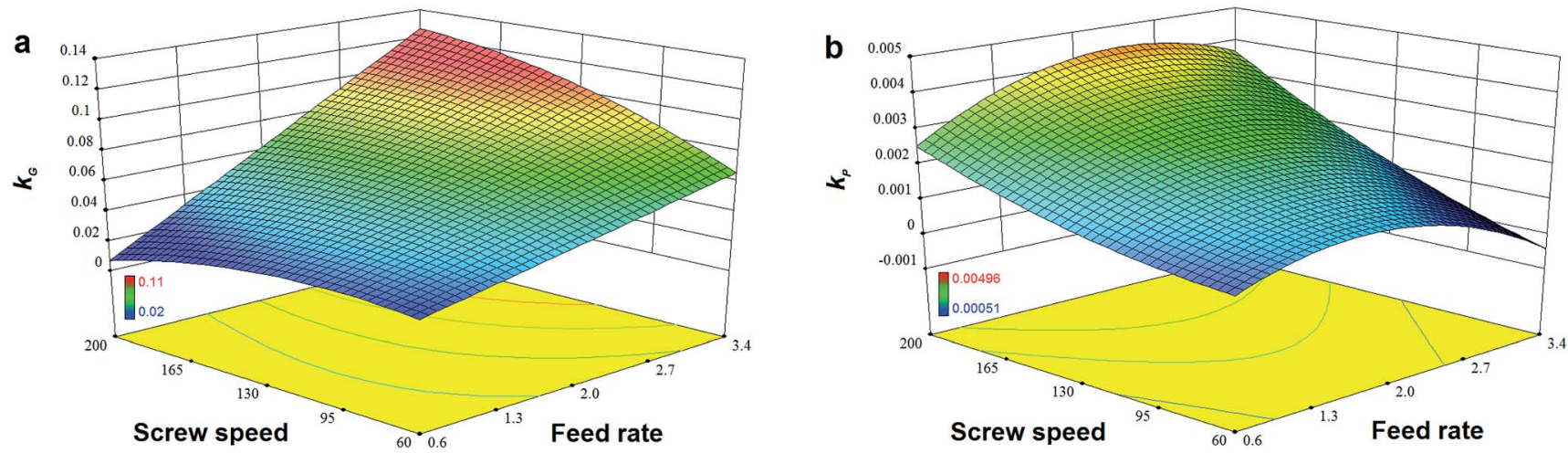

Fig. 8 Effects of feed rate and screw speed on reaction rate constant (a) $k_{G}$ of GE and (b) $k_{P}$ of TPC for high-efficiency enzymatic extrusion. 
Table 9 Results of revised model for starch gelatinization and phenolics loss based on the second order factorial central composite experimental design

\begin{tabular}{|c|c|c|c|}
\hline \multirow[b]{2}{*}{ Model } & \multirow[b]{2}{*}{ Target } & \multicolumn{2}{|l|}{$\mathrm{EE}$} \\
\hline & & $\mathrm{GE}^{a}$ & $\mathrm{TPC}^{b}$ \\
\hline$k=k_{0} \exp \left(-\frac{E}{R(T+273.15)}+\lambda_{\mathrm{f}} F+\lambda_{\mathrm{n}} N\right)$ & $\begin{array}{l}k_{0} \\
E\left(\mathrm{~kJ} \mathrm{~mol}^{-1}\right) \\
R^{2} \\
\operatorname{RMSE} \\
\lambda_{\mathrm{f}} \\
\lambda_{\mathrm{n}}\end{array}$ & $\begin{array}{l}0.02 \\
0.24 \\
0.9362 \\
8.29 \times 10^{-3} \\
0.39 \\
3.52 \times 10^{-3}\end{array}$ & $\begin{array}{l}3.02 \times 10^{6} \\
70.30 \\
0.7747 \\
4.36 \times 10^{-4} \\
-0.03 \\
8.83 \times 10^{-3}\end{array}$ \\
\hline
\end{tabular}

when the rotation speed was added, but its reaction constant $k_{\mathrm{G}}$ greatly increased (Fig. 8a). This indicates that increased $N$ shortened the residence time of starch gelatinization, and potentially inhibited the enzyme activity due to the increased mechanical energy and friction. A similar result was observed for TPC loss and its $k_{\mathrm{P}}$ with $N$ (Fig. 8b). For processing parameters, the effects of $F$ and $N$ on die temperature and pressure were irregular, but PT and DP for enzymatic extrusion decreased overall (Fig. 6a and b). The change in SME may contribute to starch gelatinization and phenolic destruction as it expressed the opposite response on $F$ and $N$ to those of GE, $c /$ $c_{0}$, and TAA (Fig. 6c). The correlation analysis also showed that $c / c_{0}$ and TAA were negatively linked to SME $(R=-0.805$ and $-0.859, p<0.01$ and 0.001 , respectively) as well as MRT $(R=$ -0.564 and -0.600 , respectively, $p<0.05$ ) (Table 8). A negative relationship was found between GE and SME $(R=-0.794, p<$ 0.01 ), which may be attributed to the mechanical impact on enzymatic activity thereby inhibiting starch gelatinization. Besides, $c / c_{0}$ had positive correlations with SFL and Pe, indicating that increased barrel fill with less axial mixing of rice would contribute to TPC retention.

\subsection{Kinetic models for high-efficiency enzymatic extrusion}

Considering the dramatic influence of $F$ and $N$ on GE and TPC during high-efficiency bio-extrusion, we calculated their $E$ values using a revised model of eqn (11). An extremely low $E$ of $0.24 \mathrm{~kJ} \mathrm{~mol}^{-1}$ was obtained for starch gelatinization (Table 9), probably due to the enzymatic attack on the starch substrate notably decreasing its reaction barrier. This data based on the experiment of high-efficiency enzymatic extrusion was much lower than that fitted from the "general enzymatic extrusion" groups using eqn (10), but even more reliable $\left(R^{2}=0.9362\right.$, RMSE $=0.0083)$. As for TPC destruction, a high $E$ of $70.30 \mathrm{~kJ}$ $\mathrm{mol}^{-1}$ was achieved and was similar to that calculated above $\left(72.87 \mathrm{~kJ} \mathrm{~mol}^{-1}\right.$ shown in Table 5). Zorić et al. ${ }^{48}$ reported a relatively low range of $8-27 \mathrm{~kJ} \mathrm{~mol}^{-1} E$ of the degradation of phenolic acids and flavonol glycosides in freeze-dried sour cherry Marasca paste. The difference between that data and the TPC in this study may be partly due to their different treatment environments, and partly due to the composition of the ingredient.

\section{Conclusions}

We concluded from the study that both macromolecules of starch and micromolecules of phenolic compounds were very unstable during traditional extrusion processing. The addition of thermomechanical energy input, local friction and shearing action in extrusion accelerated the degradation and destruction of these food ingredients by reducing their activation energies, although the residence time of the extrusion treatment was quite fast compared to other heating treatments.

When thermostable $\alpha$-amylase was introduced to achieve rapid gelatinization and liquefaction of starch, its activation energy dramatically decreased while that of the phenolics increased apparently and indirectly because of the modified reaction environment with less mechanical impact, die pressure and shear stress. Thus, the original positive relationship between the reaction rates of phenolic destruction and starch gelatinization in traditional extrusion was totally inverted by enzyme addition in terms of its kinetics.

\section{Nomenclature}

TE Traditional extrusion

EE Enzymatic extrusion

GE Extent of gelatinization (\%)

TPC Total phenolic content $\left(\mu \mathrm{g}\right.$ GAE $\left.\mathrm{g}^{-1}\right)$

TAA Total antioxidant activity $\left(\mu \mathrm{g}\right.$ TEAC $\left.\mathrm{g}^{-1}\right)$

PT Product temperature $\left({ }^{\circ} \mathrm{C}\right)$

DP Die pressure (Mpa)

SME Specific mechanical energy $\left(\mathrm{kJ} \mathrm{kg}^{-1}\right)$

$c \quad$ Concentrations of gelatinized starch after extrusion (\%)

$c_{0} \quad$ Concentrations of gelatinized starch prior to extrusion

(\%)

$C \quad$ Concentration of a component (\%)

$C(t) \quad$ Tracer concentration (\%)

$E \quad$ Activation energy (thermal-induced reaction) $\left(\mathrm{kJ} \mathrm{mol}^{-1}\right)$

$E_{0} \quad$ Activation energy in a shear-less environment $\left(\mathrm{kJ} \mathrm{mol}^{-1}\right)$

$E_{\text {a }} \quad$ Activation energy of flow $\left(\mathrm{kJ} \mathrm{mol}^{-1}\right)$

$E(t) \quad$ Exit age distribution $\left(\mathrm{s}^{-1}\right)$

$f \quad$ Concentrations of total phenolics after extrusion (\%)

$f_{0} \quad$ Concentrations of total phenolics prior to extrusion (\%)

$G \quad$ Geometrical coefficient 
$k_{0} \quad$ Pre-exponential factor

$k_{\mathrm{G}} \quad$ Degradation rate constants of starch $\left(\mathrm{s}^{-1}\right)$

$k_{\mathrm{P}} \quad$ Degradation rate constants of phenolics $\left(\mathrm{s}^{-1}\right)$

$n \quad$ Flow behavior index

Pe Peclet number

$t \quad$ Reaction time (s)

$t_{\mathrm{m}} \quad$ Mean residence time of extrusion process (s)

$\Delta t \quad$ Time interval (s)

$R \quad$ Universal gas constant $\left(\mathrm{J}\left(\mathrm{mol}^{-1} \mathrm{~K}^{-1}\right)\right)$

\section{Greek letters}

$\beta \quad$ Activation volume

$\gamma \quad$ Shear rate $\left(\mathrm{N} \mathrm{m}^{-2}\right)$

$\zeta \quad$ Reaction order

$\eta \quad$ Apparent viscosity (cP)

$\eta_{0}$ Pre-exponential factor of apparent viscosity

$\lambda_{\mathrm{m}}$ Dependence parameters of $M$ calculated by genetic algorithm

$\lambda_{\mathrm{f}} \quad$ Dependence parameters of $F$ calculated by genetic algorithm

$\lambda_{\mathrm{n}}$ Dependence parameters of $N$ calculated by genetic algorithm

$\sigma^{2}$ Variance

$\sigma_{\theta} \quad$ Standardized $\sigma$

$\tau \quad$ Proportional to shear stress

$\phi \quad$ Torque $(\mathrm{Nm})$

\section{Acknowledgements}

This study was supported by Natural Science Foundation of China (No. 31501418 and No. 31601413) National "Thirteenth Five-Year" Plan for Science \& Technology Support of China (No.2016YFD0400304), Nature Science Foundation of Jiangsu Province (No. BK20160168) and Graduate Student Innovation Project of Jiangsu Province (No. KYLX16_1314).

\section{References}

1 M. Patel, X. Zhang and A. Kumar, Renewable Sustainable Energy Rev., 2016, 53, 1486-1499.

2 P. Bhanja and A. Bhaumik, Fuel, 2016, 185, 432-441.

3 S. Govindasamy, O. H. Campanella and C. G. Oates, J. Food Eng., 1997, 32, 403-426.

4 M. P. Adhikari, R. Adhikari, R. G. Shrestha, R. Rajendran, L. Adhikari, P. Bairi, R. R. Pradhananga, L. K. Shrestha and K. Ariga, Bull. Chem. Soc. Jpn., 2015, 88, 1108-1115.

5 T. Ebrahimi and S. Shahriari, Bull. Chem. Soc. Jpn., 2016, 89, 565-572.

6 Y. Lin and G. W. Huber, Energy Environ. Sci., 2009, 2, 68-80.

7 S. J. You, I. G. Baek and E. D. Park, Appl. Catal., A, 2013, 466, 161-168.

8 A. Duque, P. Manzanares, I. Ballesteros, M. J. Negro, J. M. Oliva, F. Saez and M. Ballesteros, Fuel, 2014, 134, 448-454.
9 S. Lee, Y. Teramoto and T. Endo, Bioresour. Technol., 2009, 100, 275-279.

10 E. Xu, Z. Wu, F. Wang, H. Li, X. Xu, Z. Jin and A. Jiao, Food Bioprocess Technol., 2015, 8, 589-604.

11 B. W. Solihin, M. H. Kim, B. S. Im, J. Y. Cha and G. H. Ryu, Food Sci. Biotechnol., 2007, 16, 381-385.

12 A. Duque, P. Manzanares, I. Ballesteros, M. J. Negro, J. M. Oliva, A. González and M. Ballesteros, Bioresour. Technol., 2014, 158, 262-268.

13 C. H. Choi, J. S. Kim and K. K. Oh, Biomass Bioenergy, 2013, 54, 211-218.

14 S. Zhang, Y. Xu and M. A. Hanna, Appl. Biochem. Biotechnol., 2011, 166, 458-469.

15 M. Bhattacharya and M. A. Hanna, J. Food Sci., 1987, 52, 764766.

16 X. Zhang and S. S. Wang, J. Food Sci., 1994, 59, 1137-1143.

17 M. Guha, S. Z. Ali and S. Bhattacharya, Int. J. Food Sci. Technol., 1998, 33, 259-266.

18 C. Brennan, M. Brennan, E. Derbyshire and B. K. Tiwari, Trends Food Sci. Technol., 2011, 22, 570-575.

19 E. Xu, Z. Wu, J. Long, F. Wang, X. Xu, Z. Jin and A. Jiao, J. Funct. Foods, 2015, 17, 214-226.

20 A. Altan, K. L. McCarthy and M. Maskan, Int. J. Food Sci. Technol., 2009, 44, 1263-1271.

21 M. Hirth, A. Leiter, S. M. Beck and H. P. Schuchmann, J. Food Eng., 2014, 125, 139-146.

22 G. R. Velderrain-Rodríguez, H. Palafox-Carlos, A. WallMedrano, J. F. Ayala-Zavala, C. Y. O. Chen, M. RoblesSánchez, H. Astiazaran-García, E. Alvarez-Parrilla and G. A. González-Aguilar, Food Funct., 2014, 5, 189-197.

23 N. R. Dlamini, J. R. N. Taylor and L. W. Rooney, Food Chem., 2007, 105, 1412-1419.

24 R. Repo-Carrasco-Valencia, J. Peña, H. Kallio and S. Salminen, J. Cereal Sci., 2009, 49, 219-224.

25 T. De Pilli, J. Legrand, A. Derossi and C. Severini, J. Food Process Eng., 2010, 33, 65-82.

26 T. De Pilli, J. Legrand, R. Giuliani, A. Derossi and C. Severini, Food Technol. Biotechnol., 2009, 7, 404-412.

27 W. Cai and L. L. Diosady, J. Food Sci., 1993, 58, 872-875.

28 V. J. Davidson, D. Paton, L. L. Diosady and L. J. Rubin, J. Food Sci., 1984, 49, 1154-1157.

29 L. L. Diosady, D. Paton, N. Rosen, L. J. Rubin and C. Athanassoullias, J. Food Sci., 1985, 50, 1697-1699.

30 S. Ilo and E. Berghofer, J. Food Sci., 2003, 68, 496-502.

31 R. Guzman-tello and J. C. Cheftel, Int. J. Food Sci. Technol., 1987, 22, 549-562.

32 S. Ilo and E. Berghofer, J. Food Sci., 1998, 63, 312-316.

33 J. T. Chien, H. C. Hsieh, T. H. Kao and B. H. Chen, Food Chem., 2005, 91, 425-434.

34 O. Levenspiel, Chem. React. Eng., 1972, 253-325.

35 X. Zhao, Y. Wei, Z. Wang, B. Zhang, F. Chen and P. Zhang, J. Food Sci., 2011, 76, R134-R142.

36 J. K. Lin and D. J. Armstrong, Trans. ASAE, 1990, 33, 19711978.

37 E. Xu, Z. Wu, J. Long, F. Wang, X. Pan, X. Xu, Z. Jin and A. Jiao, Food Bioprocess Technol., 2015, 8, 1958-1973. 
38 V. L. Singleton and J. A. Rossi, Am. J. Enol. Vitic., 1965, 16, 144-158.

39 W. Brand-Williams, M. E. Cuvelier and C. berset, LWT-Food Sci. Technol., 1995, 28, 25-30.

40 B. A. Acosta-Estrada, J. A. Gutiérrez-Uribe and S. O. SernaSaldívar, Food Chem., 2014, 152, 46-55.

41 Q. Liu, J. Li, B. Kong, P. Li and X. Xia, Int. J. Dairy Technol., 2014, 67, 220-228.

42 E. A. Ozer, E. N. Herken, S. Guzel, P. Ainsworth and S. Ibanoglu, Int. J. Food Sci. Technol., 2006, 41, 289-293.

43 B. Soison, K. Jangchud, A. Jangchud, T. Harnsilawat, K. Piyachomkwan, C. Charunuch and W. Prinyawiwatkul, Int. J. Food Sci. Technol., 2014, 49, 2067-2075.
44 C. Sarawong, R. Schoenlechner, K. Sekiguchi, E. Berghofer and P. K. W. Ng, Food Chem., 2014, 143, 33-39.

45 P. Sharma, H. S. Gujral and B. Singh, Food Chem., 2012, 131, 1406-1413.

46 M. E. van der Veen, D. G. van Iersel, A. J. van der Goot and R. M. Boom, Biotechnol. Prog., 2004, 20, 1140-1145.

47 S. S. Wang, W.-c. Chiang, A.-i. Yeh, B. Zhao and I.-h. Kim, J. Food Sci., 1989, 54(5), 1298-1301.

48 Z. Zorić, V. Dragović-Uzelac, S. Pedisić, Ž. Kurtanjek and I. E. Garofulić, Food Technol. Biotechnol., 2014, 52, 101-108. 